\title{
Effect of alkali treatment on wettability and thermal stability of individual bamboo fibers
}

\author{
Hong Chen ${ }^{1} \cdot$ Wenfu Zhang ${ }^{2} \cdot$ Xuehua Wang $^{1} \cdot$ Hankun Wang ${ }^{3} \cdot$ Yan Wu $^{1} \cdot$ Tuhua Zhong $^{4} \cdot$ Benhua Fei $^{3}$
}

Received: 27 October 2017 / Accepted: 24 February 2018 / Published online: 12 March 2018

(c) The Japan Wood Research Society 2018

\begin{abstract}
The aim of this study is to examine the wettability and thermal properties of individual bamboo fibers after alkali treatment. The individual bamboo fibers were treated by sodium hydroxide $(\mathrm{NaOH})$ solution with varying concentrations $(6,8,10,15$ and $25 \%$ ) followed by freeze-drying treatment. The surface analysis of alkali-treated individual bamboo fibers was characterized by atomic force microscope. Water droplet on the individual fiber surface was observed with drop shaper analyzer and the contact angles on fiber surface were also measured. Thermal properties were further studied by thermogravimetric analysis. The results indicated that alkali treatment resulted in the increase in surface roughness of individual bamboo fibers. Alkali treatment with low $\mathrm{NaOH}$ concentration could enhance the wettability of treated individual bamboo fibers, and while the wettability was reduced with alkali treatment at high concentration $(25 \%)$. Thermal analysis revealed that the onset of decomposition and the maximum decomposition were moved to higher temperature after alkali treatment at low $\mathrm{NaOH}$ concentrations $(6,8$, and $10 \%)$, suggesting the improvement in the thermal stability of treated individual bamboo fibers, while the thermal stability was compromised after alkali treatment at higher concentrations (15 and 25\%).
\end{abstract}

Keywords Bamboo fiber · Alkali treatment $\cdot$ Surface analysis $\cdot$ Wettability $\cdot$ Thermal stability

\section{Introduction}

With concerns of environment, there has been an increasing effort to develop degradable and environmentally friendly products from biomass resources. Natural fiber has been considered as a promising alternative to synthetic fiber because of its advantage which is high strength with low density

Electronic supplementary material The online version of this article (https://doi.org/10.1007/s10086-018-1713-0) contains supplementary material, which is available to authorized users.

Tuhua Zhong

tuhua.zhong@wsu.edu

Benhua Fei

feibenhua@icbr.ac.cn

1 College of Furnishings and Industrial Design, Nanjing Forestry University, Nanjing 210037, China

2 Zhejiang Forestry Academy, Hangzhou 310023, China

3 International Center for Bamboo and Rattan, Beijing 100102, China

4 Composite Materials and Engineering Center, Washington State University, Pullman, WA 99164, USA in addition to its inherit feature such as renewability and biodegradability. Among natural fibers manufactured from different types of bioresources, bamboo fibers have drawn particular attentions due to the rapid growth of bamboo and the extraordinary mechanical properties (e.g., average tensile strength 1.43-1.69 GPa, and modulus of elasticity (MOE) 32-34.6 GPa) [1]. In general, bamboo is recommended to harvest at 3-5 years for products in furniture and construction industry [2]. For the use in craft, bamboo could be harvested at an even younger age depending on the species [2]. One of the difficulties that have prevented the use of bamboo fiber in composites is the hydrophilic nature adversely affects adhesion with hydrophobic matrix [3]. Another major drawback of bamboo fiber used in composites seems to be the limited thermal stability. The melting temperatures of typically used thermoplastics as matrix (e.g., polypropylene, polyethylene) need to be below or equal to the degradation temperature of bamboo fiber $[3,4]$.

Chemical treatment of natural fibers can change surface condition and chemical composition to obtain desirable properties $[5,6]$. There are many chemical treatments such as sodium hydroxide $(\mathrm{NaOH})[7-10], \mathrm{HNO}_{3}-\mathrm{KClO}_{3}$ [11], $\mathrm{NaClO}$ [12], and benzoate [13]. The alkali treatment 
has been regarded as a relatively inexpensive and effective method to modify the fiber [14, 15]. Many researchers have reported the structure and properties of different alkalitreated natural fibers from wood [16], jute [17], kenaf [18], aloe vera cactus [19], oil palm [20], sugar palm [21], coir pith [6], etc. It was found that different fibers obtained different properties with alkali treatment. Alkali treatment can improve the potential moisture adsorption of wood fiber, but reduce water retention behavior of coir pith fiber. With alkali treatment, the thermal stability of fibers from aloe vera cactus, coir pith and oil palm increased, while that of jute fibers and sugar palm fibers decreased.

Furthermore, there were several researches on the structure and mechanical properties of bamboo strips and dusts [7, 8], bamboo fiber bundles [9, 22] and bamboo pulp [23]. Chemical composition, a lattice transformation from cellulose I to cellulose II, and mechanical properties of bamboo fibers changed differently according to the concentration of alkali treatment. In our previous study, the microstructure and mechanical properties of alkali-treated individual bamboo fibers were investigated [24]. When treated by alkali with higher concentration, microfibril aggregates in bamboo fiber changed from a randomly interwoven structure to a granular structure and cellulose I was transformed to cellulose II. The tensile strength and MOE of individual bamboo fibers decreased with alkali treatment. However, how does the alkali treatment affect the wettability and thermal stability of individual bamboo fibers? To the best of our knowledge, there is no report on the wettability and thermal stability of individual bamboo fibers treated by alkali with different concentrations.

In this research, individual bamboo fibers were treated by $\mathrm{NaOH}$ solution with different concentrations. Surface topography, contact angles and thermal properties of alkali-treated individual bamboo fibers were characterized by atomic force microscope (AFM), drop shaper analyzer (DSA) and thermogravimetric analysis (TGA). The effects of $\mathrm{NaOH}$ concentration on the wettability and thermal stability of individual bamboo fibers were examined.

\section{Experimental}

\section{Samples preparation}

Bamboo (Neosinocalamus affinis) was obtained from the culm where it was $2 \mathrm{~m}$ high from the ground in Chengdu, Sichuan Province, China. Individual bamboo fibers were isolated by immersing small bamboo strips $(30 \mathrm{~mm}$ longitudinal and $2 \times 2 \mathrm{~mm}$ in cross-section) in a chemical solution (one part 30\% hydrogen peroxide and one part glacial acetic acid) at $65{ }^{\circ} \mathrm{C}$ for $18.5 \mathrm{~h}$ [25]. Then, individual bamboo fibers were dipped in $6,8,10,15$ and $25 \% \mathrm{NaOH}$ solution at room temperature $\left(23 \pm 2{ }^{\circ} \mathrm{C}\right)$ for $2 \mathrm{~h}$. The fiber mass to alkali weight ratio was $1: 100$. Then, individual fibers were thoroughly washed with deionized water to remove $\mathrm{NaOH}$ from fibers until the $\mathrm{pH}$ was around 7. Fiber suspensions were frozen in liquid nitrogen and dried for $24 \mathrm{~h}$ in a freeze dryer.

\section{Atomic force microscope}

The individual bamboo fibers were observed in Burker Icon atomic force microscope (CA, USA). The specimens were characterized using the same method described in our previous research [24]. Untreated individual bamboo fibers were characterized as control.

\section{Contact angle measurement}

The contact angles of individual fibers were measured with a KRÜSS DSA100 (Hamburg, Germany) at $25^{\circ} \mathrm{C}$ and $20 \%$ RH (relative humidity). Individual bamboo fibers were mounted on a slatted platform with double-side tape. A charge-coupled device (CCD) camera recorded the process from the water droplet dropped on the fiber until disappeared (as shown in Fig. 1). The baseline for a sessile drop static contact angle measurement was made at the liquid-solid interphase with droplet size held to a constant $10 \mu \mathrm{L}$. Contact angle measurements were calculated using the ellipse method at a rate of 72 frames/s in the DSA 3 software as described in our previous work [12]. Fifteen replications were measured for each treated and untreated sample.

\section{Thermogravimetric analysis}

The thermal stability and degradation behavior of alkalitreated and -untreated individual bamboo fibers were

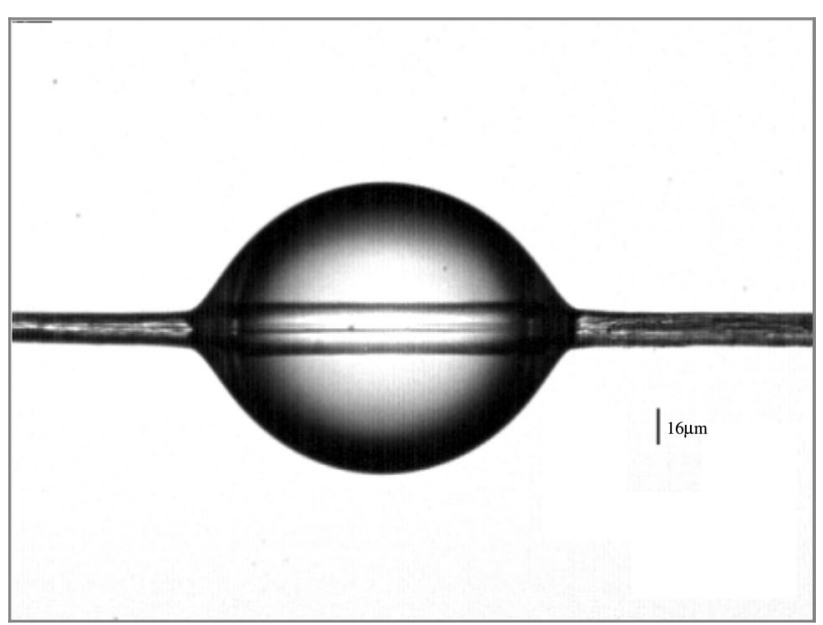

Fig. 1 Water droplet on an individual bamboo fiber 
characterized by STA409PC thermogravimetric analyzer (Netzsch, Germany). All the measurements were conducted under a nitrogen atmosphere and heated up at a constant rate of $10{ }^{\circ} \mathrm{C} / \mathrm{min}$ from room temperature to $600{ }^{\circ} \mathrm{C}$.

\section{Results and discussion}

\section{Fiber surface analysis}

Figure 2 shows the topographical views of individual bamboo fibers treated by $\mathrm{NaOH}$ solution with different concentrations, respectively. As shown in Fig. 2, alkali-treated surface exhibited rougher surface topography compared with the untreated one. Additional information is shown in online resource Fig. S1. The removal of hemicellulose might in part account for rougher surface of alkali-treated individual bamboo fibers, because microfibril aggregates were prone to aggregate easily when the cell wall lost lignin and hemicellulose. As reported in our previous research [24], lignin has been removed in all fibers during the isolation process, and hemicellulose was partly removed by the alkali treatment with concentration at 6 and $8 \%$, and completely removed at 10,15 , and $25 \%$. Besides, cellulose I was transformed to cellulose II as treated by alkali with concentration at 15 and $25 \%$. With increasing alkali concentration at higher level $(10,15$ and $25 \%)$, the surface of individual bamboo fibers became more and more flaky and grooved (Fig. 2d-f). That
Fig. 2 2D AFM images of individual fibers treated by alkali with different concentrations (a 0 , b $6 \%, \mathbf{c} 8 \%$, d $10 \%$, e $15 \%$, f $25 \%$ )
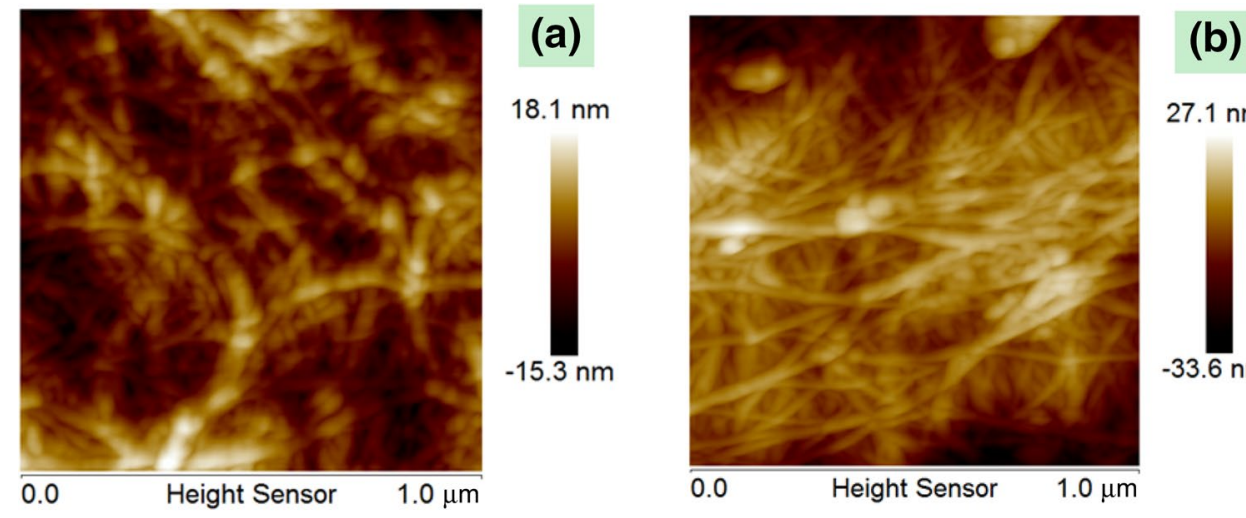

$27.1 \mathrm{~nm}$
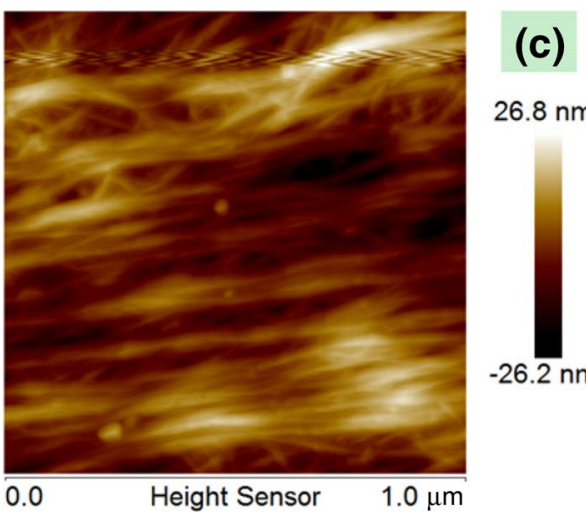

$26.8 \mathrm{~nm}$
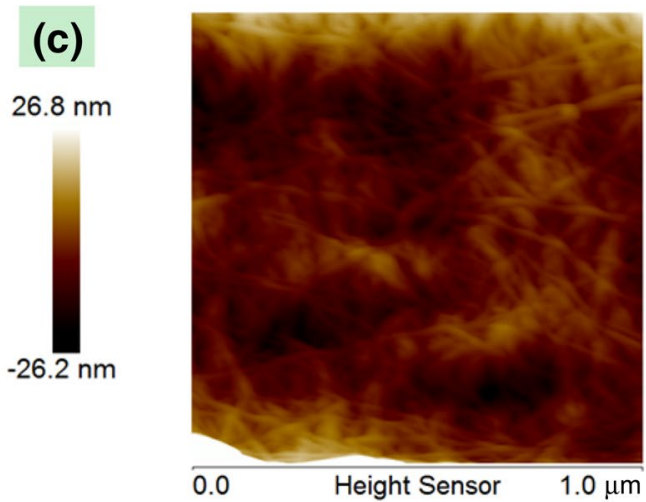

(d)

$67.3 \mathrm{~nm}$
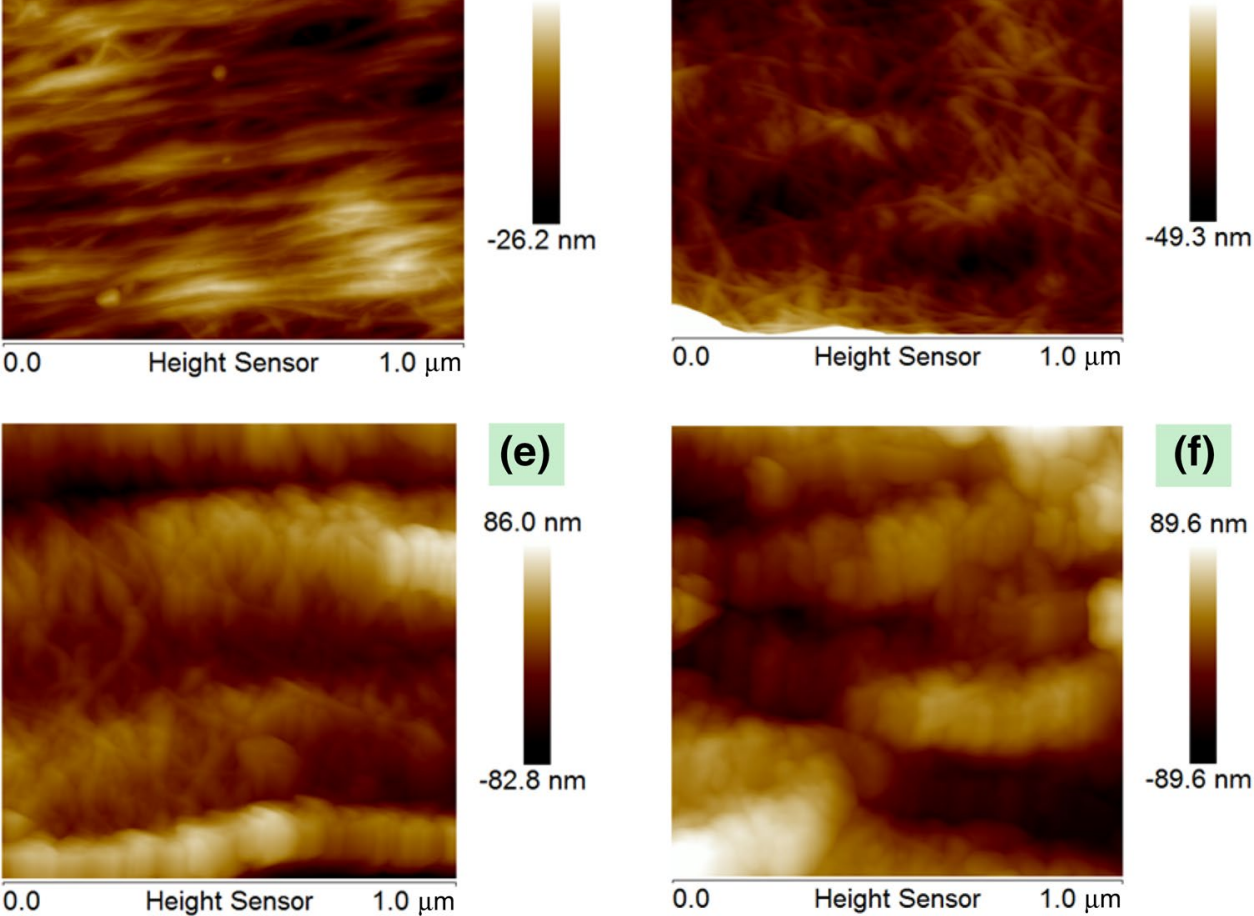

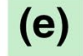

$86.0 \mathrm{~nm}$

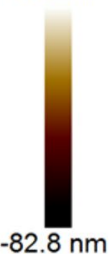

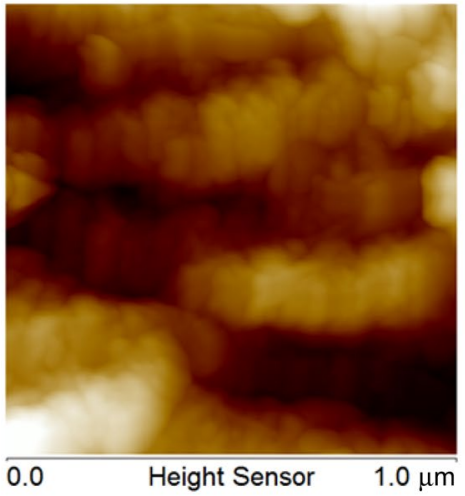

$89.6 \mathrm{~nm}$

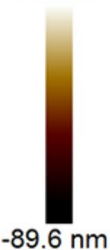

$-89.6 \mathrm{~nm}$ 
might be mainly attributed to the combination of hemicellulose removal and conversion of cellulose I to cellulose II [24]. As reported, microfibrils were swollen and more granular in cellulose II than in cellulose I [26]. The surface topography of alkali-treated individual bamboo fibers in this study well agreed with the observation of other natural fibers after alkali treatment reported by other researchers $[6$, 18, 27-29].

As shown in Fig. 3, like untreated individual bamboo fiber, the surface roughness of individual bamboo fibers with
6 or $8 \% \mathrm{NaOH}$ treatment in $x$-axis direction (longitudinal axis of fiber, parallel to the axis marked with $0-1 \mu \mathrm{m}$ in Fig. 2) was similar to that in $y$-axis direction (perpendicular to longitudinal axis of fiber, perpendicular to the axis marked with $0-1 \mu \mathrm{m}$ in Fig. 2). However, with the alkali concentration increased to higher level (10,15 and 25\%), the surface roughness in $y$-axis direction was much higher than that in $x$-axis direction. That might be attributed to more aggregation of microfibril aggregates in the $y$-axis direction after alkali treatment. As illustrated by previous researches,
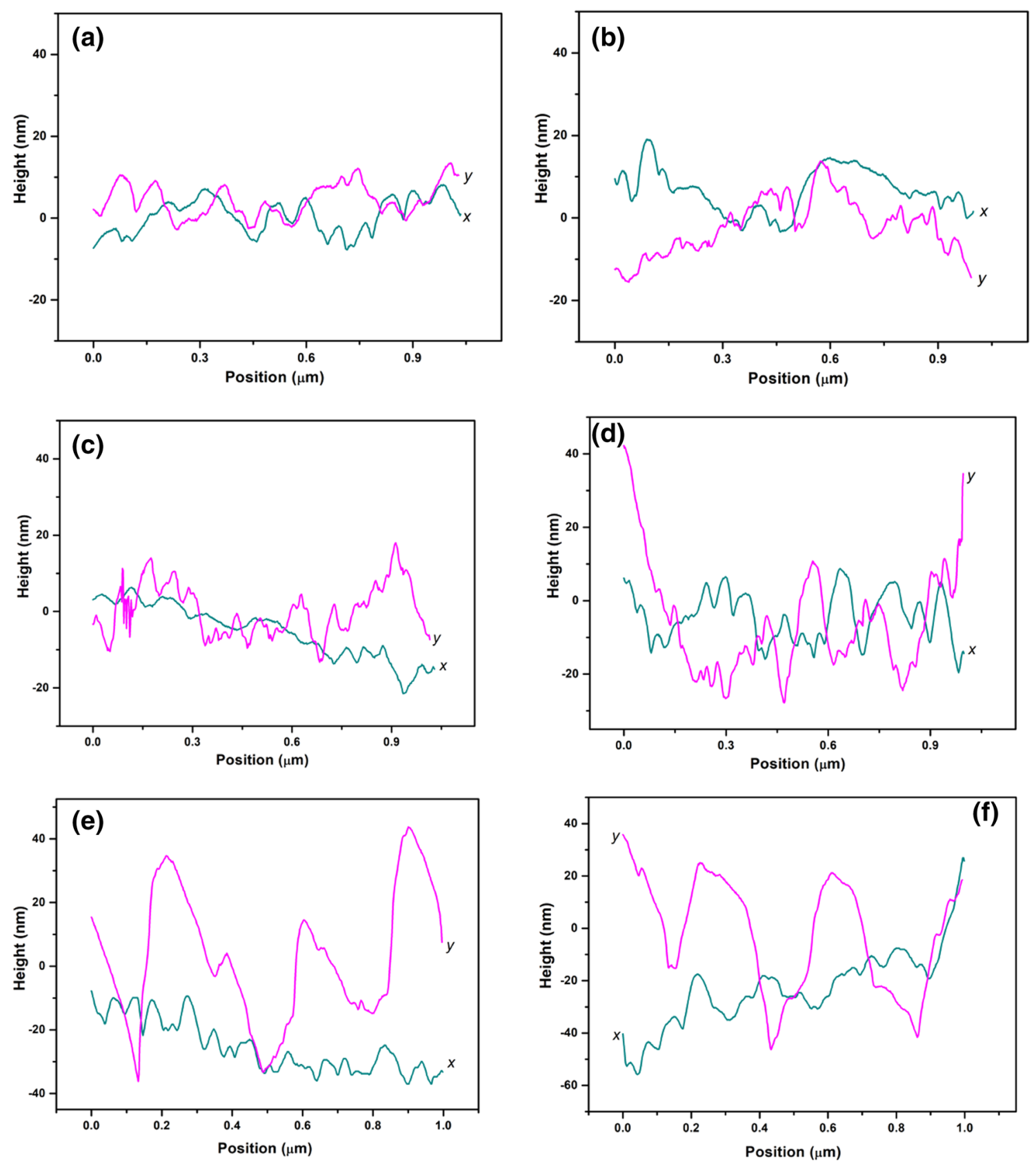

Fig. 3 The height of fiber surface treated by alkali with different concentrations (a $0, \mathbf{b} 6 \%, \mathbf{c} 8 \%$, d $10 \%$, e $15 \%$, f $25 \%), x$-the direction parallel to longitudinal axis of fiber, $y$ - the direction perpendicular to longitudinal axis of fiber 
when non-cellulosic components lignin and hemicellulose were removed in the isolation process and alkali treatment, respectively, microfibrils would aggregate through hydrogen bonding [30]. Bamboo fiber exhibited a polylamellate structure with alternating broad and narrow lamellae [31]. Microfibrils in the broad lamellae were oriented almost parallel to the longitudinal axis of the fiber $\left(2-20^{\circ}\right)$, while microfibrils in narrow lamellae oriented almost perpendicular to the cell axis $\left(85-90^{\circ}\right)$ [31]. With the elimination of the cementing materials in the bamboo fiber, more microfibrils were prone to aggregate in $y$-axis direction (perpendicular to longitudinal axis of fiber) rather than in $x$-axis direction (longitudinal axis of fiber).

\section{Contact angles}

The evaporation or penetration time of water droplet in the video recorded by CCD camera and diameter of individual bamboo fibers are presented in Table 1 . When a water droplet dropt on an individual bamboo fiber, both evaporation and penetration phenomena occurred simultaneously. It was found that the evaporation or penetration time decreased with alkali treatment. All chemical composition, diameter and surface topography of individual bamboo fibers would affect the evaporation or penetration time. It is a sophisticated process which need be further studied in the future.

Figure 4 shows water contact angles of untreated and alkali-treated individual bamboo fibers. The individual bamboo fiber with $6 \% \mathrm{NaOH}$ treatment exhibited the lowest water contact angle. With continuing to increase alkali concentration, water contact angles started to slightly increase. When the alkali concentration increased up to $25 \%$, the water contact angle increased to the highest value. These changes in the water contact angles might be explained by the change in the combined effects of the chemical composition and surface roughness during the alkali treatment. It is reported that surface roughness of the fibers and the accessibility of hydroxyl groups on the surface are two important factors affecting the surface wettability [30, 32]. As discussed in the surface analysis section in this paper and in our previous research [24], hemicellulose was partly removed with 6,8 and $10 \% \mathrm{NaOH}$

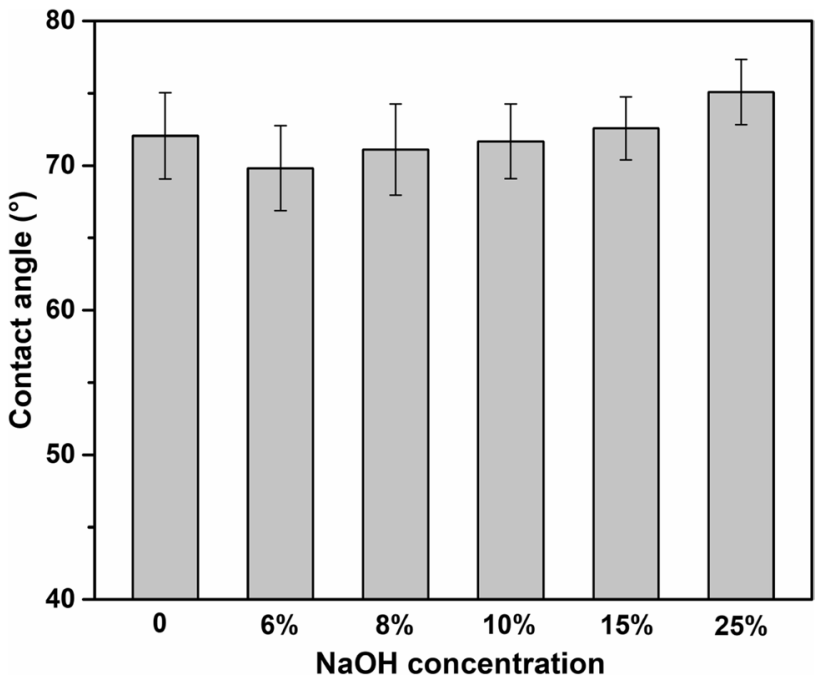

Fig. 4 Contact angles of individual bamboo fibers treated by alkali with different concentrations

treatment, surface roughness increased and the accessibility of hydroxyl groups decreased with increasing $\mathrm{NaOH}$ concentration. At low $\mathrm{NaOH}$ treatment, the effect of surface roughness on the wettability may overwhelm hydroxyl group effect, that might be explain why contact angles of treated fibers were lower compared with untreated bamboo fiber. As reported by Ouajai and Shanks [33], the transition of cellulose I into II with higher concentration of $\mathrm{NaOH}$ resulted in the decrease of crystallinity. Furthermore, cellulose II had a high ability of absorption in amorphous region, while the density of amorphous region of cellulose I was higher [34]. Besides, the roughness of bamboo fiber increased when treated by alkali with higher concentration as shown in Fig. 3. However, the accessibility of hydroxyl groups was reduced with the removal of hemicellulose and lignin when $\mathrm{NaOH}$ concentration increased to 15 and 25\%, as cellulose closely packed itself with hydrogen bonding [30]. The combination of these changes resulted in the further increase of contact angle, the contact angle of bamboo fibers with $25 \% \mathrm{NaOH}$ treatment was even higher than that of the untreated fibers.

Table 1 The evaporation or penetration time of water droplet in the video recorded by CCD camera and diameter of individual bamboo fibers

\begin{tabular}{lllllll}
\hline $\mathrm{NaOH}$ concentration & Untreated & $6 \%$ & $8 \%$ & $10 \%$ & $15 \%$ & $25 \%$ \\
\hline $\begin{array}{c}\text { Evaporation or pen- } \\
\text { etration time }(\mathrm{s})\end{array}$ & $201.71( \pm 42.77)$ & $197.20( \pm 26.05)$ & $196.93( \pm 23.35)$ & $193.18( \pm 38.09)$ & $171.54( \pm 40.94)$ & $171.29( \pm 37.96)^{\mathrm{a}}$ \\
\begin{tabular}{l} 
Diameter $^{\mathrm{b}}(\mu \mathrm{m})$ \\
\hline
\end{tabular} & $16.46( \pm 4.47)$ & $15.23( \pm 1.33)$ & $11.47( \pm 3.55)$ & $9.75( \pm 4.1)$ & $7.42( \pm 2.05)$ & $8.02( \pm 1.57)^{\mathrm{a}}$ \\
\hline
\end{tabular}

$C C D$ charge-coupled device

${ }^{\text {a }}$ Standard deviation

${ }^{\mathrm{b}}$ This diameter was measured by Chen et al. [24] 


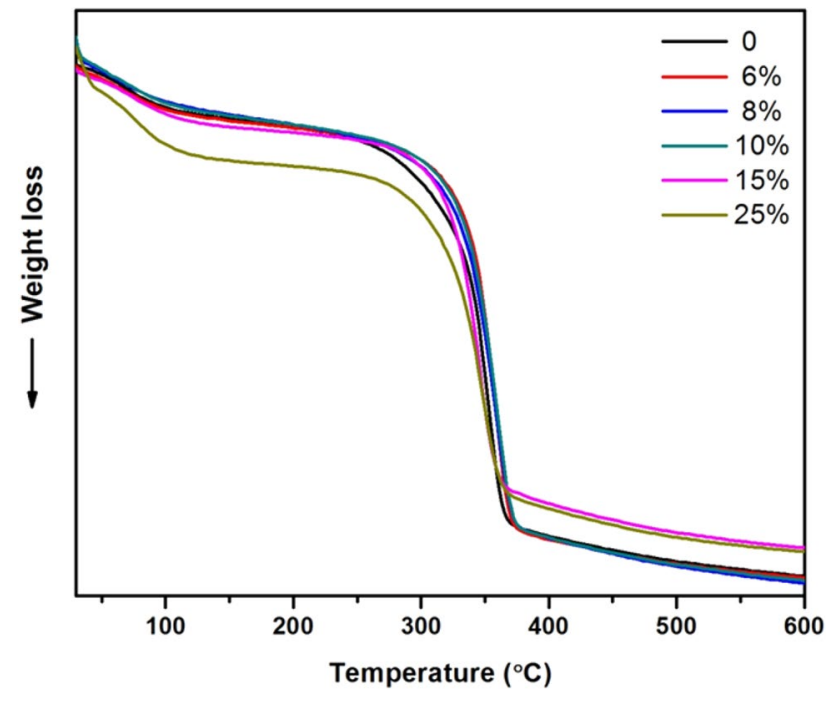

Fig. 5 TGA curves of individual bamboo fibers treated by alkali with different concentrations

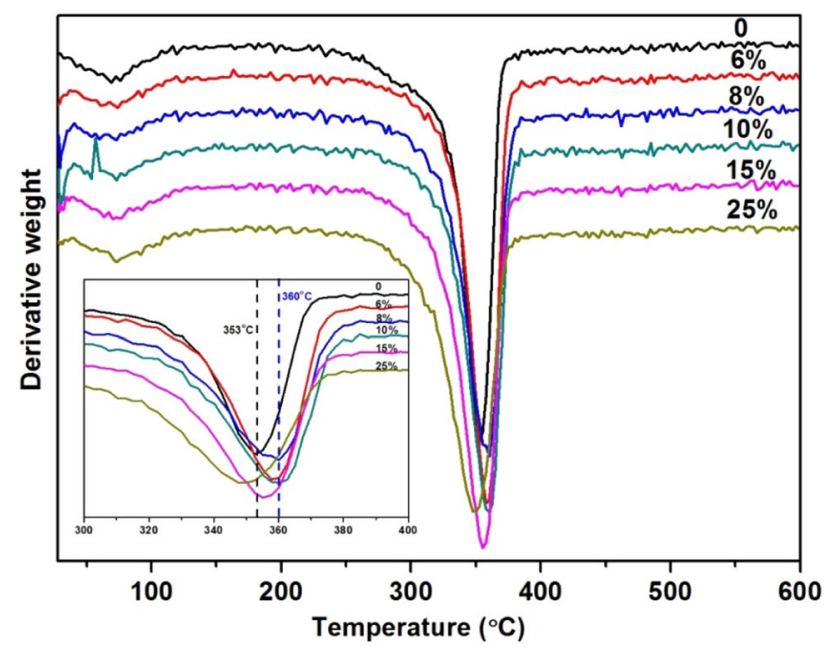

Fig. 6 DTG curves of individual bamboo fibers treated by alkali with different concentrations

\section{Thermogravimetric analysis}

Thermal stability of untreated and alkali-treated individual bamboo fibers with various $\mathrm{NaOH}$ concentrations was investigated by TGA. The TGA curves and its corresponding derivative thermogravimetric (DTG) curves are shown in Figs. 5 and 6, respectively. As shown in TGA and DTG curves, all the untreated and alkali-treated exhibited two distinct weight loss stages at $30-150$ and $200-600{ }^{\circ} \mathrm{C}$, respectively. The first weight loss stage was attributed to the evaporation of water, and the second weight loss stage in the region $200-600{ }^{\circ} \mathrm{C}$ was assigned to the decomposition of polysaccharide including cellulose, hemicellulose and lignin materials $[19,35]$. The onset of decomposition of untreated individual bamboo fibers is at lower temperature compared to treated bamboo fiber with low $\mathrm{NaOH}$ concentrations $(6$, 8 , and $10 \%$ ). It might be attributed to the existence of hemicellulose in the untreated fibers, which reported that main component xylose in hemicellulose would decompose at around $180-280{ }^{\circ} \mathrm{C}$ [35].

$T_{\max }$ is the decomposition temperature corresponding to the maximum weight loss and relates to maximum decomposition temperature, which is also an important indicator of the thermal stability of the materials [36]. The maximum decomposition temperature of untreated individual bamboo fibers occurred at $353{ }^{\circ} \mathrm{C}$, which is a little higher than that of natural fibers from other bioresources, such as sugar palm fiber $\left(348^{\circ} \mathrm{C}\right)[21]$, and aloe vera cactus fiber $\left(350^{\circ} \mathrm{C}\right)$ [19]. When bamboo fibers were treated with $6 \% \mathrm{NaOH}$, the maximum decomposition temperature increased to $358{ }^{\circ} \mathrm{C}$. With increasing $\mathrm{NaOH}$ concentration to $10 \%$, the maximum decomposition temperature increased up to $360{ }^{\circ} \mathrm{C}$. It indicated that the thermal stability of individual bamboo fibers can be improved by alkali treatment with proper concentration. However, when treated with alkali at higher concentration from 15 to $25 \%$, the maximum decomposition temperature decreased from 355 to $347{ }^{\circ} \mathrm{C}$, respectively. The corresponding onset temperature of decomposition also shifted to lower temperature. The lower onset temperature and reduced maximum decomposition temperature might be in part ascribed to the conversion of cellulose I form in bamboo fibers into cellulose II form after 15 and $25 \%$ $\mathrm{NaOH}$ treatment [24]. However, as reported previously that better thermal stability was obtained when cellulose transformed from I to II, no matter presented in hemp fiber or nanofiber sheet $[33,37]$. The thermal stability of cellulosic fibers might be influenced by the combined effects of different factors. The exact reason for the decrease in the thermal stability in this study was not fully understood. The combination of the change in crystallinity and the transformation of cellulose might be mainly ascribed to the reduction in the lower onset temperature and maximum decomposition temperature of bamboo fibers. The results indicated that alkali-treated individual bamboo fibers with desired thermal stability are still favorable reinforcing materials for the use in the thermoplastics.

\section{Conclusion}

In this work, surface topography, contact angles, and thermal stability of individual bamboo fibers were investigated for alkali treatment with various concentrations. The results suggested that the alkali concentration is an important factor affecting surface topography, wettability and thermal properties of individual bamboo fibers after alkali treatment. 
(1) The surface roughness of alkali-treated individual bamboo fiber increased with increasing $\mathrm{NaOH}$ concentrations. It was found that more flaky and grooved structure of bamboo fibers with 15 and $25 \% \mathrm{NaOH}$ treatment was observed because of the transformation of cellulose I into cellulose II and re-aggregation of microfibrils after the removal of non-cellulosic materials in the bamboo fibers. It is also found that microfibrils are prone to aggregate in the direction perpendicular to longitudinal axis of fiber.

(2) Water contact angles on the bamboo fibers surface first decreased at $6 \% \mathrm{NaOH}$ concentration treatment and then gradually increased with increasing $\mathrm{NaOH}$ concentrations. It might be ascribed to the change in the combined effects of surface roughness, chemical composition and the accessibility of hydroxyl groups on the fiber surface.

(3) The alkali treatment with low concentrations $(6,8$ and $10 \%$ ) could improve thermal stability of bamboo fiber because of the removal of hemicellulose from bamboo fibers, while alkali treatment with higher concentrations (15 and $25 \%$ ) would compromise thermal stability. That might result from combined effects of different factors (transformation of cellulose, crystallinity, etc.) which need be further studied in the future.

Acknowledgements We would like to appreciate the Basic Scientific Research Funds of International Center for Bamboo and Rattan (1632016007), and National Natural Science Foundation of China (31500474, 31370563).

\section{References}

1. Yu Y, Tian GL, Wang HK, Fei BH, Wang G (2011) Mechanical characterization of single bamboo fibers with nanoindentation and microtensile technique. Holzforschung 65:113-119

2. Liese W, Köhl M (eds) (2015) Bamboo: the plant and its uses. Springer, Cham

3. Ren D, Yu ZX, Zhang XX, Wang HK, Wang H, Yu Y (2017) Quantitative characterization of the interface between bamboo fiber and polypropylene with pull-out test and nanomechanical imaging. J Mater Sci 52(3):1296-1307

4. Fei P, Fei BH, Yan Y, Xiong HG, Tan J (2014) Thermal properties and crystallization behavior of bamboo fiber/high-density polyethylene composites: nano-TiO ${ }_{2}$ effects. J Appl Poly Sci 131(3). https://doi.org/10.1002/APP.39846

5. Alix S, Philippe E, Bessadok A, Lebrun L, Morvan C, Marais S (2009) Effect of chemical treatments on water sorption and mechanical properties of flax fibres. Bioresour Technol 100(20):4742-4749

6. Narendar R, Dasan KP (2014) Chemical treatments of coir pith: morphology, chemical composition, thermal and water retention behavior. Compos Part B Eng 56:770-779

7. Das M, Chakraborty D (2006) Influence of alkali treatment on the fine structure and morphology of bamboo fibers. J Appl Polym Sci 102(5):5050-5056
8. Das M, Chakraborty D (2008) Evaluation of improvement of physical and mechanical properties of bamboo fibers due to alkali treatment. J Appl Polym Sci 107(1):522-527

9. Liu Y, Hu H (2008) X-ray diffraction study of bamboo fibers treated with $\mathrm{NaOH}$. Fibers Polym 9(6):735-739

10. Ray D, Sarkar BK (2001) Characterization of alkali-treated jute fibers for physical and mechanical properties. J Appl Polym Sci 80(7):1013-1020

11. Liu DG, Song JW, Anderson DP, Chang PR, Hua Y (2012) Bamboo fiber and its reinforced composites: structure and properties. Cellulose 19:1449-1480

12. Chen H, Wang G, Cheng HT (2011) Properties of single bamboo fibers isolated by different chemical methods. Wood Fiber Sci 43(2):1-10

13. Amel BA, Paridah MT, Sudin R, Anwar UMK, Hussein AS (2013) Effect of fiber extraction methods on some properties of kenaf bast fiber. Ind Crops Prod 46:117-123

14. Nakagaito AN, Yano H (2008) Toughness enhancement of cellulose nanocomposites by alkali treatment of the reinforcing cellulose nanofibers. Cellulose 15:323-331

15. Reddy KO, Maheswari CU, Shukla M, Song JI, Rajulu AV (2013) Tensile and structural characterization of alkali treated Borassus fruit fine fibers. Compos Part B Eng 44(1):433-438

16. Xu YJ, Xu Y, Yue XP (2017) Changes of hydrogen bonding and aggregation structure of cellulose fiber due to microwaveassisted alkali treatment and its impacts on the application as fluff pulp. Cellulose 24:967-976

17. Sinha E, Rout SK (2008) Influence of fibre-surface treatment on structural, thermal and mechanical properties of jute. J Mater Sci 43:2590-2601

18. Ariawan D, Mohd Ishak ZA, Salim MS, Mat Taib R, Ahmad Thirmizir MZ (2017) Wettability and interfacial characterization of alkaline treated kenaf fiber-unsaturated polyester composites fabricated by resin transfer molding. Polym Compos 38(3):507-515

19. Balaji AN, Nagarajan KJ (2017) Characterization of alkali treated and untreated new cellulosic fiber from Saharan aloe vera cactus leaves. Carbohydr Polym 174:200-2008

20. Norul Izani M, Paridah MT, Anwar UMK, Mohd Nor MY, H'ng PS (2013) Effects of fiber treatment on morphology, tensile and thermogravimetric analysis of oil palm empty fruit bunches fibers. Compos Part B Eng 45(1):1251-1257

21. Rashid B, Leman Z, Jawaid M, Ghazali MJ, Ishak MR (2016) Physiochemical and thermal properties of lignocellulosic fiber from sugar palm fiber: effect of treatment. Cellulose 23:2905-2916

22. Wang F, Zhou SJ, Li L, Zhang XP (2017) Changes in the morphological-mechanical properties and thermal stability of bamboo fibers during the processing of alkali treatment. Polym Compos. https://doi.org/10.1002/pc.24332

23. Yang ZP, Xu SW, Ma XL, Wang SY (2008) Characterization and acetylation behavior of bamboo pulp. Wood Sci Technol 42:621-632

24. Chen H, Yu Y, Zhong T, Wu Y, Li Y, Wu Z, Fei B (2017) Effect of alkali treatment on microstructure and mechanical properties of individual bamboo fibers. Cellulose 24(1):333-347

25. Wang G, Shi S, Wang JW, Yu Y, Cao SP, Cheng HT (2011) Tensile properties of four types of individual cellulosic fibers. Wood Fiber Sci 43(4):353-364

26. Eronen P, Österberg M, Jääskeläinen AS (2009) Effect of alkaline treatment on cellulose supramolecular structure studied with combined confocal Raman spectroscopy and atomic force microscopy. Cellulose 16(2):167-178

27. Chandrasekar M, Ishak MR, Sapuan SM, Leman Z, Jawaid M (2017) A review on the characterisation of natural fibres and 
their composites after alkali treatment and water absorption. Plast Rubber Compos 46(3):119-136

28. Chen CJ, Chen G, Li X, Guo H, Wang G (2017) The influence of chemical treatment on the mechanical properties of windmill palm fiber. Cellulose 24(4):1611-1620

29. Tian G, Chen B, Qi S, Niu H, Han E, Wu D (2016) Enhanced surface free energy of polyimide fibers by alkali treatment and its interfacial adhesion behavior to epoxy resins. Compos Interface 23(2):145-155

30. Chowdhury MNK, Beg MDH, Khan MR, Mina MF (2013) Modification of oil palm empty fruit bunch fibers by nanoparticle impregnation and alkali treatment. Cellulose 20(3):1477-149

31. Parameswaran N, Liese W (1976) On the fine structure of bamboo fibres. Wood Sci Technol 10(4):231-246

32. Young RA (1976) Wettability of wood pulp fibers: applicability of methodology. Wood Fiber Sci 8(2):120-128
33. Ouajai S, Shanks RA (2005) Composition, structure and thermal degradation of hemp cellulose after chemical treatments. Polym Degrad Stabil 89(2):327-335

34. Ishikawa A, Okano T, Sugiyam J (1997) Fine structure and tensile properties of ramie fibres in the crystalline form of cellulose I, II, III $_{\mathrm{I}}$ and $\mathrm{IV}_{\mathrm{I}}$. Polymer 38(2):463-468

35. Kabir MM, Wang H, Lau KT, Cardona F (2013) Effects of chemical treatments on hemp fibre structure. Appl Surf Sci 276:13-23

36. Zhong T, Oporto SG, Jaczynski J, Jiang C (2015) Nanofibrillated cellulose and copper nanoparticles embedded in polyvinyl alcohol films for antimicrobial applications. BioMed Res Int 2015:1-8

37. Wang H, Li D, Yano H, Abe K (2014) Preparation of tough cellulose II nanofibers with high thermal stability from wood. Cellulose 21(3):1505-1515 